\title{
Peningkatan Kompetensi Siswa SMK-PP Negeri Jambi Melalui Pelatihan Budidaya Jamur Tiram
}

\author{
Husda Marwan*1, Sri Mulyati², Reni Yustien ${ }^{3}$ \\ 1,2 Program Studi Agroekoteknologi, Fakultas Pertanian, Universitas Jambi \\ ${ }^{3}$ Program Studi Akuntansi, Fakultas Ekonomi dan Bisnis, Universitas Jambi \\ *e-mail: husda_marwan@unja.ac.id¹, sri_mulyati@unja.ac.id², reni.yustien@unja.ac.id ${ }^{3}$
}

\begin{abstract}
SMK-PP Jambi is one of the vocational schools owned by the Jambi government to produce graduates who have basic skills in agricultural science. The purpose of this activity is to : (1) Introduce the prospects and potential of oyster mushroom cultivation business; (2) Providing skills to students on how to grow oyster mushrooms. Stages of activities carried out are: (1) Counseling about the prospects and potential of oyster mushroom cultivation; (2) Training of oyster mushroom cultivation : making of planting media (baglog), planting mushroom seeds on baglog, maintenance and harvesting of oyster mushrooms. The results of the evaluation of the activities showed that: (1) The extension activities were able to increase students' knowledge about the potential for oyster mushroom cultivation; (2) The training that has been done has been able to improve students' knowledge and skills about oyster mushroom cultivation.
\end{abstract}

Kata kunci: Oyster mushroom, SMK, training

\begin{abstract}
Abstrak
SMK-PP Negeri Jambi merupakan salah satu sekolah kejuruan yang dimiliki oleh pemerintah Provinsi Jambi untuk menghasilkan lulusan yang mempunyai keterampilan dasar dalam bidang ilmu pertanian. Tujuan kegiatan ini adalah : (1) Mengenalkan kepada siswa tentang prospek dan potensi usaha jamur tiram; (2) Memberikan keterampilan cara budidaya jamur tiram. Tahapan kegiatan yang dilakukan adalah : (1) Penyuluhan tentang prospek dan potensi budidaya jamur tiram; (2) Pelatihan budidaya jamur tiram : pembuatan media tanam (baglog), penanaman bibit jamur pada baglog, pemeliharaan dan pemaanenan jamur tiram. Hasil evaluasi kegiatan menunjukkan bahwa : (1) Kegiatan penyuluhan mampu meningkatkan pengetahuan siswa tentang potensi usaha budidaya jamur tiram; (2) Pelatihan yang telah dilakukan mampu meningkatkan pengetahuan dan keterampilan siswa tentang budidaya jamur tiram.
\end{abstract}

Keywords: Jamur tiram, Pelatihan, SMK

\section{PENDAHULUAN}

Sekolah Menengah Kejuruan Pembangunan Pertanian (SMK-PP) Negeri Jambi yang didirikan pada tanggal 25 Januari 1969 merupakan salah lembaga pendidikan kejuruan yang dimiliki oleh pemerintah Provinsi Jambi untuk menghasilkan lulusan yang mempunyai keterampilan dasar dalam bidang ilmu pertanian. SMK-PP Negeri Jambi mempunyai dua jurusan yaitu : Agribisnis Perkebunan dan Agribisnis Tanaman Pangan/Holtikultura.

SMK-PP Negeri Jambi mempunyai misi melaksanakan pembelajaran yang berjiwa wirausaha, mampu mengembangkan sistem dan usaha agribisnis yang berdaya saing. Untuk meningkatkan kompetensi lulusan dalam bidang wirausaha, siswa-siswa SMK-PP Negeri Jambi perlu mendapatkan kompetensi tambahan, terutama kompetensi yang dapat meningkatkan jiwa kewirausahaan lulusan. Kurikulum sekolah yang berbasis kompetensi sebenarnya dapat mendorong dan membimbing siswanya untuk mempunyai ketrampilan hidup (life skill). Menurut Wahzudik et al. (2018) proses pengembangan kurikulum di satuan pendidikan SMK telah sesuai dan menggunakan landasan pengembangan kurikulum, terdapat dukungan dari berbagai stakeholder namun masih terbatas, proses pendampingan kurikulum belum maksimal karena di tiap sekolah tidak ada sumber daya khusus ahli pengembang kurikulum.

Selain itu, kurikulum berbasis sekolah yang diterapkan oleh pemerintah saat ini dapat memacu sekolah untuk mempunyai keunggulan tertentu. Keterbatasan sumber daya manusia, 
sarana dan prasarana sekolah menyebabkan penerapan kurikulum berbasis kompetensi belum terlaksana secara optimal. Menurut Atmam et al. (2019) kurangnya kegiatan yang berhubungan dengan bidang non akademik dapat menyebabkan kurangnya kreativitas siswa.

Pelatihan budidaya jamur tiram merupakan salah satu kompetensi yang dapat diberikan untuk meumbuhkan jiwa kewirausahaan siswa SMK-PP Negeri Jambi. Jamur tiram merupakan salah satu produk pertanian yang dapat dikembangkan karena potensi pemasarannya yang cukup besar, baik sebagai sayuran segar dan juga dapat diolah menjadi nugget, rendang, abon, krispi jamur tiram (Susi et al., 2017), dan tepung (Yuliani et al., 2018. Jamur tiram juga mengandung senyawa beta-glucan yang dapat merangsang sistim kekebalan tubuh. Jamur tiram terbukti efektif dan bermanfaat untuk pengobatan diabetes, kanker, dan infeksi mikroba (Mowsumi dan Choudhury, 2010).

Pengembangan budidaya jamur tiram di SMK-PP Negeri Jambi juga didukung oleh ketersediaan lahan yang luas dilingkungan sekolah ini. SMK-PPN Jambi mempunyai areal seluas $676.426 \mathrm{~m}^{2}$ yang sebagian besar belum dimanfaatkan. Potensi lain yang dapat mendukung pengembangan budidaya jamur tiram di sekolah ini adalah keberadaan siswa di asrama-asrama yang disediakan sekolah. Hal ini memungkinkan pengelolaan budidaya jamur tiram dapat dilakukan secara intensif karena siswa mempunyai banyak waktu untuk beraktivitas dalam kegiatan budidaya jamur tiram.

Kegiatan pelatihan budidaya jamur tiram ini bertujuan untuk : (1) Mengenalkan kepada siswa SMK-Pertanian Jambi tentang prospek dan potensi budidaya jamur tiram; (2) Memberikan keterampilan kepada siswa-siswi SMK-PP Negeri Jambi tentang cara membuat budidaya jamur tiram, dimulai dari persiapan media tanam, penanaman bibit jamur, pemeliharaan, dan panen jamur tiram.

\section{METODE}

\section{Tempat dan Waktu Pelaksanaan}

Kegiatan Program Kemitraan Masayarakat (PKM) ini dilaksanakan di SMK-PP Negeri Jambi (Kelurahan Jembatan Mas, Kecamatan Pemayung, Kabupaten Batanghari) pada bulan Juli sampai Oktober 2019. Kegiatan PKM yang dilaksanakan terdiri dari penyuluhan, pelatihan dan pembuatan percontohan budidaya jamur tiram.

\section{Penyuluhan tentang Prospek dan Potensi Budidaya Jamur Tiram}

Tujuan kegiatan ini adalah meningkatkan pengetahuan siswa SMK-PP Negeri Jambi tentang prospek dan potensi ekonomi jamur tiram. Penyuluhan dilakukan dengan metode androgogy (pendidikan untuk orang dewasa), dilanjutkan dengan diskusi tentang materi penyuluhan dan pembentukan kelompok pelatihan budidaya jamur tiram.

Materi penyuluhan yang akan disampaikan kepada siswa- SMK-PP Negeri Jambi adalah : (1) Pengenalan jamur tiram dan prospek ekonomi jamur tiram; (2) Teknik budidaya jamur tiram, meliputi : persiapan bibit jamur, media tanam, penanaman, pemeliharaan tanaman, dan panen.

\section{Pelatihan Budidaya Jamur Tiram}

Kegiatan pelatihan diikuti oleh 19 siswa SMK-PP Negeri Jambi yang diseleksi dari peserta yang mengukuti kegiatan penyuluhan. Kegiatan ini dilakukan secara berkala selama 12 minggu, dimana masing-masing peserta pelatihan melakukan praktek terhadap semua materi pelatihan yang diberikan.

Kegiatan pelatihan yang dilakukan meliputi : (1) Cara perbanyakan bibit jamur tiram (Gunawan, 2000); (2) Cara pembuatan media tanaman (baglog) jamur tiram (Wiardani, 2010; Susilawati dan Raharjo, 2010); (3) Pembuatan rumah jamur tiram (Achmad et al., 2011); (4) Cara menanam bibit jamur tiram ke dalam baglog jamur; (5) Pemeliharaan baglog dan pemanenan jamur tiram. 


\section{Evaluasi Kegiatan Pengabdian Kepada Masyarakat}

Evaluasi terhadap kegiatan pengabdian di SMK-PP Negeri Jambi dilakukan melalui kuisioner yang diberikan kepada seluruh peserta sebelum dilakukan kegiatan penyuluhan. Evaluasi dilakukan terhadap pengetahuan peserta tentang jamur tiram. Evaluasi terhadap kegiatan pelatihan dilakukan untuk mengetahui penguasaan peserta terhadap keterampilan yang diberikan selama pelatihan dan aspek manfaat pelaksanaan kegiatan program kemitraan masyarakat ini bagi siswa SMK-PP Negeri Jambi.

Kuisiner evaluasi disusun dalam bentuk pertanyaan dengan jawaban yang tertutup (jawaban "sudah, kurang, belum". Jawaban kuisioner siswa dianalisis untuk mendapat persentase jawaban masing-masing pertanyaan yang diberikan.

\section{HASIL DAN PEMBAHASAN}

\section{Penyuluhan Prospek Budidaya Jamur Tiram kepada Siswa SMK-PP Negeri Jambi}

Kegiatan penyuluhan dilakukan di aula SMK-PP Negeri Jambi yang dihadiri oleh 88 peserta, terdiri dari pimpinan dan siswa SMK-PP Negeri Jambi, serta beberapa masyarakat disekitar sekolah yang ingin mengetahui tentang budidaya jamur tiram. Kegiatan diawali dengan penyampaian kuisioner untuk mengetahui tingkat pengetahuan siswa tentang materi penyuluhan yang akan disampaikan. Penyuluhan dilakukan dengan metode ceramah dan diskusi. Agar materi sosialisasi dapat diterima dan dipahami oleh siswa SMK-PP Negeri Jambi, penyampaian materi penyuluhan didukung dengan media in focus untuk menyampaikan bahan presentasi dan pemutaran video budidaya jamur tiram secara ringkas. Pemateri menjelaskan secara rinci tentang cara budidaya jamur tiram yang dimulai dari persiapan bibit sampai dengan proses pemanenan jamur tiram (Gambar 1).

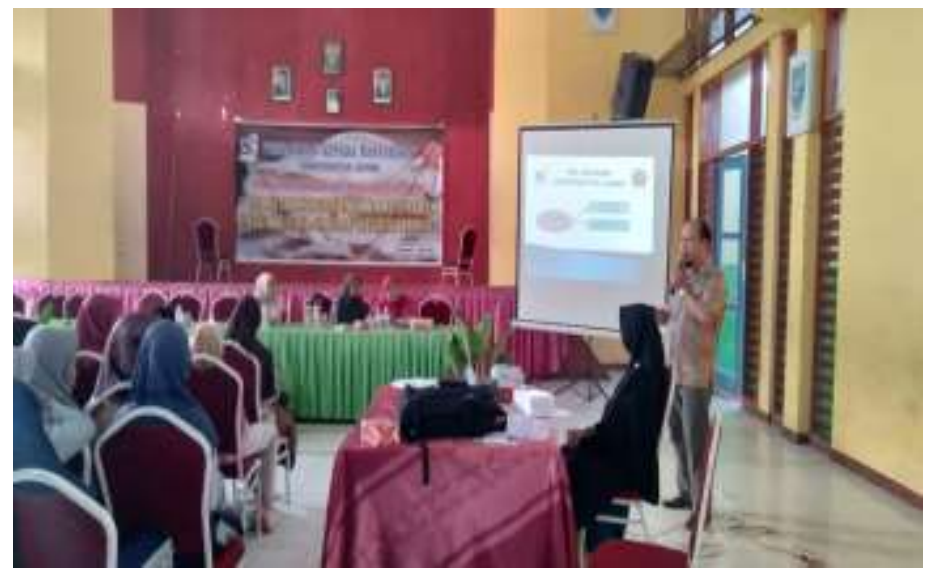

Gambar 1. Penyampaian materi penyuluhan tentang prospek dan cara budidaya jamur tiram di SMK-PP Negeri Jambi

Setelah dilakukan penyampaian materi penyuluhan, dilakukan diskusi tentang kegiatan budidaya jamur tiram, kemudian dilakukan penyusunan rencana kegiatan selanjutnya, yaitu :

1. Pemilihan siswa yang akan mengikuti pelatihan.

Agar kegiatan pelatihan yang dilakukan dapat memberikan keterampilan yang maksimal bagi siswa, Wakil Kepala SMK-PP bidang Kesiswaan akan menyeleksi siswa yang akan mengikuti pelatihan berdasarkan tingkat motivasi dan penyebaran daerah asal siswa yang bersangkutan.

2. Pimpinan SMK-PP Negeri Jambi menetapkan lokasi pembuatan rumah jamur (kubung) yang akan digunakan untuk pelatihan budidaya jamur tiram. 


\section{Pelatihan Budidaya Jamur Tiram}

Kegiatan pelatihan yang dilaksanakan adalah pembuatan baglog jamur tiram, sterilisasi baglog, penanaman bibit jamur tiram ke dalam baglog, pemeliharaan baglog di rumah jamur, dan pemanenan jamur tiram.

Masing-masing siswa peserta pelatihan mempraktek cara membuat baglog jamur tiram sesuai dengan cara yang telah dicontohkan (Gambar 2). Media tanam jamur tiram terdiri dari campuran serbuk kayu gergaji dengan dedak, kapur dan gips sesuai takaran untuk mendapatkan komposisi media yang merata (Wiardani, 2010; Susilawati dan Raharjo, 2010). Media tanam dimasukkan ke dalam plastik polipropile (PP) dengan kepadatan tertentu agar miselia jamur dapat tumbuh dengan baik. Ujung plastik disatukan dan dipasang cincin dari potongan paralon pada bagian leher plastik sehingga bungkusan akan menyerupai botol.
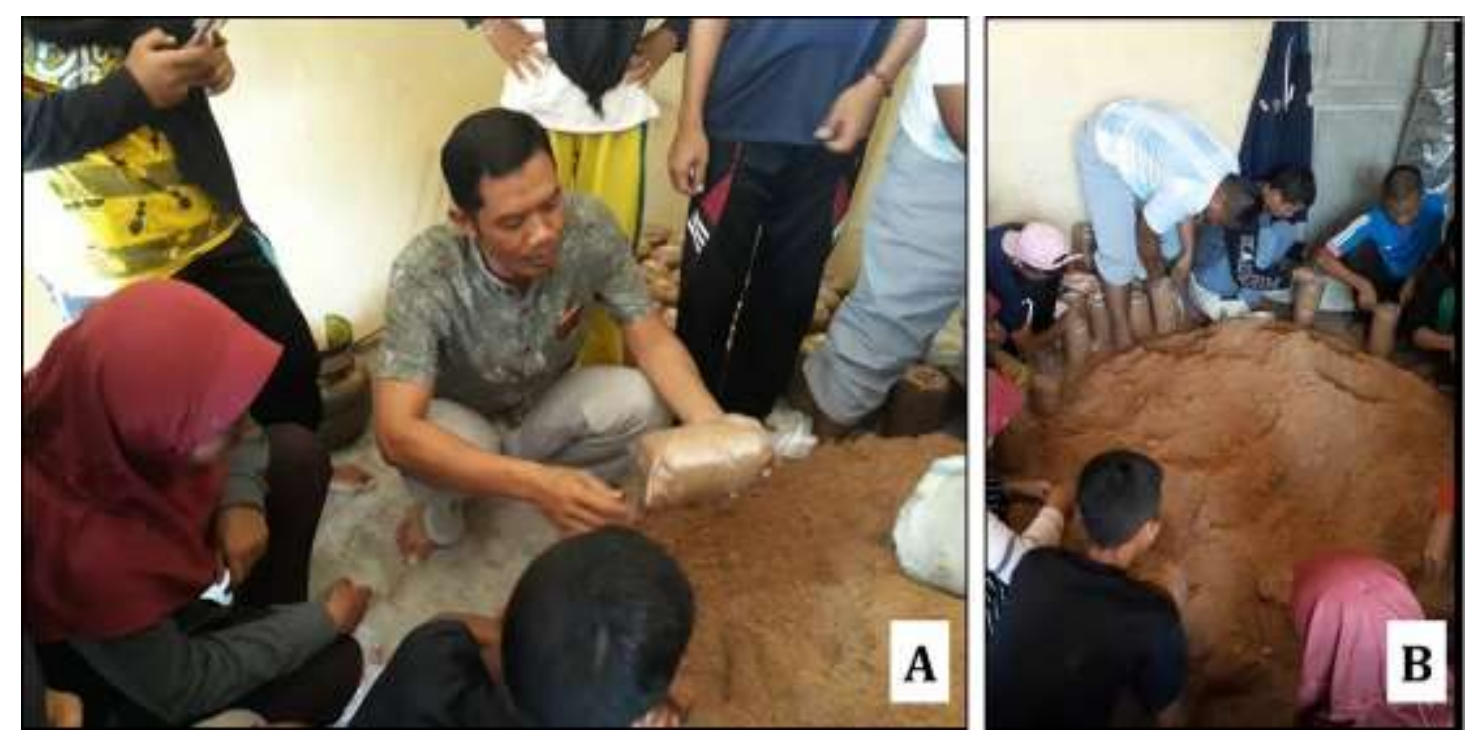

Gambar 2. Pelatihan pembuatan baglog:

(A) Pengarahan cara memasukkan media tanaman ke dalam plastik PP oleh narasumber;

(B) Siswa peserta pelatihan mempraktekkan cara membuat baglog.

Pada pelatihan ini, masing-masing peserta diwajibkan untuk menyiapkan 50 baglog jamur yang akan digunakan untuk pelatihan penanaman bibit jamur, pemeliharaan, serta panen jamur tiram. Baglog disterilisasi untuk menonaktifkan mikroba yang dapat menganggu pertumbuhan jamur tiram. Sterilisasi dilakukan pada suhu $70^{\circ} \mathrm{C}$ selama $5-8$ jam. Setelah proses sterilisasi, dilakukan proses pendinginan untuk menurunkan suhu baglog sehingga tidak mengganggu pertumbuhan bibit jamur. Pendinginan dilakukan $8-12$ jam sebelum dinokulasi sampai temperatur media tanam $30-35^{\circ} \mathrm{C}$.

Pada tahap pelatihan selanjutnya, masing-masing peserta pelatihan melakukan proses penanaman bibit jamur tiram ke dalam baglog, inkubasi baglog dan pemindahan baglog ke rumah jamur (Gambar 3). Penanaman bibit jamur adalah proses pemindahan sejumlah kecil miselia jamur dari biakan induk ke dalam baglog yang telah disediakan. Tujuannya adalah menumbuhkan miselia jamur pada media tanam hingga menghasilkan jamur yang siap panen. Kegiatan inokulasi bibit jamur dilakukan dalam ruang steril dalam kondisi aseptik untuk menghindari kontaminasi dari mikroba lainnya. Sebanyak satu sendok teh bibit jamur tiram (miselia) diletakkan ke dalam baglog, kemudian baglog yang telah diisi bibit ditutup dengan kapas kembali. Baglog yang telah dinokulasi diinkubasi pada suhu $22-28{ }^{\circ} \mathrm{C}$ selama 20-30 hari, hingga seluruh permukaan ditumbuhi oleh miselia jamur berwarna putih merata, selanjutnya baglog dipindahkan ke dalam rumah jamur. 


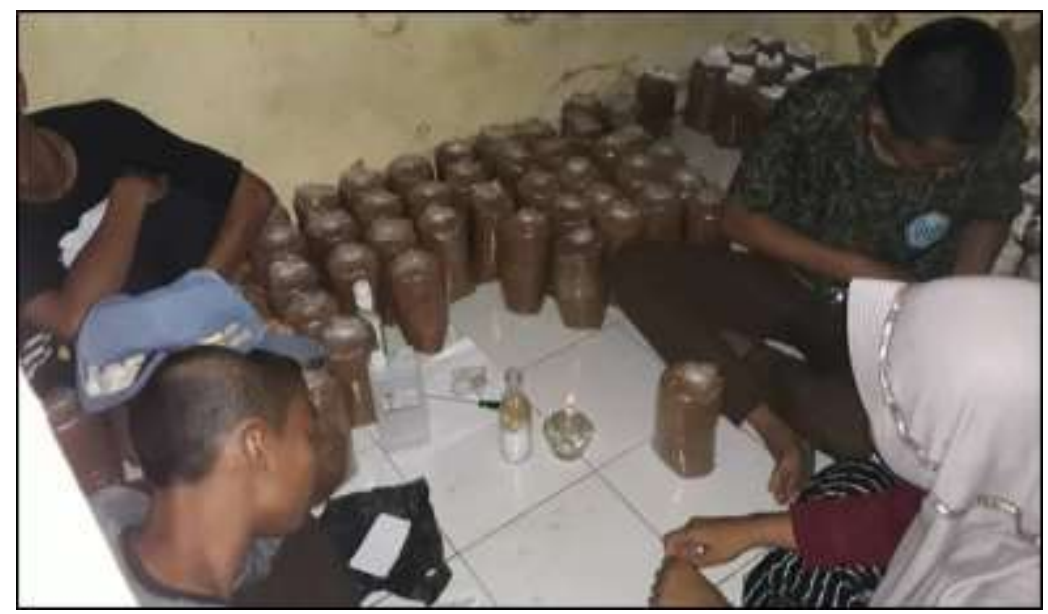

Gambar 3. Pelatihan penanaman bibit jamur tiram ke dalam baglog

Baglog yang tumbuh baik dipindahkan ke dalam rumah jamur dengan cara disusun pada rak-rak yang telah disediakan. Rumah jamur yang digunakan dalam kegiatan pelatihan ini berukuran 4 × 6 m dengan bahan rangka menggunakan baja ringan, atap alkan, dan dinding menggunakan dua lapis paranet. Pada bagian dalam rumah jamur dibuat empat baris rak jamur ( 2 baris pada bagian dinding dan 2 baris pada bagian tengah) dengan kapasitas sekitar 1.500 baglog jamur (Gambar 4A).
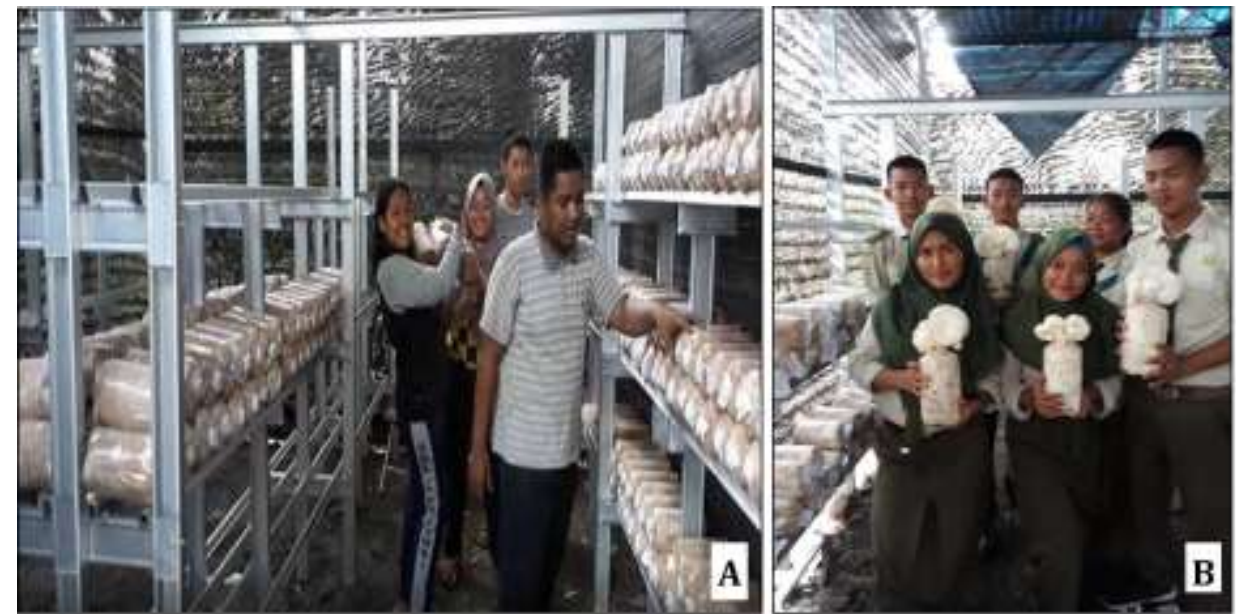

Gambar 4. (A) Pemeliharaan baglog dalam rumah jamur;

(B) Pemanenan jamur tiram oleh peserta pelatihan

Baglog yang miseliumnya sudah putih dan terjadi penebalan dibuka cincin dan kapas penutupnya agar jamur bisa tumbuh. Baglog ini dirawat dengan melakukan penyiraman secara kabut untuk mempercepat pertumbuhan tubuh buah jamur. Kegiatan pemeliharaan ini dilakukan secara bergilir oleh peserta pelatihan. Kegiatan pemanenan telah dapat dilakukan 4 minggu setelah baglog dipelihara di dalam rumah jamur (Gambar 4B). Masing-masing peserta pelatihan berhasil melakukan kegiatan budidaya jamur tiram sampai panen dengan tingkat keberhasilan jumlah baglog yang tumbuh jamur berbeda-beda. Baglog yang tidak berhasil menumbuhkan jamur disebabkan oleh kontaminasi media oleh jamur lain.

\section{Evaluasi Kegiatan Pengabdian Kepada Masyarakat}

Evaluasi terhadap kondisi awal peserta pelatihan menunjukkan bahwa peserta pelatihan belum banyak mengetahui dan mengenal jamur tiram. Sebanyak $78.9 \%$ peserta pelatihan belum pernah mengetahui tentang jamur tiram, $84.2 \%$ peserta pelatihan belum pernah mengkonsumsi 
jamur tiram, dan semua peserta pelatihan belum mengetahui cara budidaya jamur tiram dan belum pernah mengikuti kegiatan pelatihan budidaya jamur tiram. Hasil analisis kuisioner tentang kondisi awal peserta pelatihan dapat dilihat pada Gambar 5.

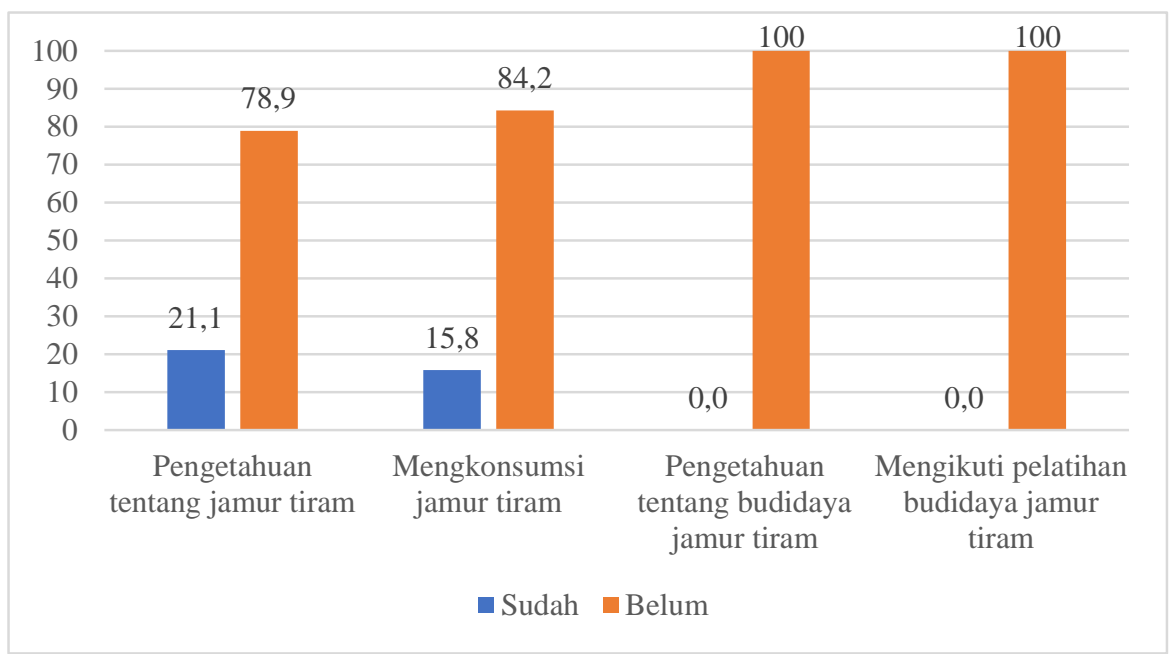

Gambar 5. Pengetahuan siswa SMK-PP Negeri Jambi tentang budidaya jamur tiram sebelum dilakukan kegiatan penyuluhan dan pelatihan

Setelah dilakukan kegiatan penyuluhan dan pelatihan, terjadi peningkatan pengetahuan dan keterampilan siswa tentang budidaya jamur tiram. Hal ini ditunjukkan dengan persentase peserta pelatihan yang memberikan jawaban "sudah" pada setiap pertanyaan kuisioner tentang kegiatan pelatihan yang telah dilakukan, kecuali pada pertanyaan tentang komposisi media tanam jamur tiram. Persentase peserta pelatihan yang "sudah mengetahui" komposisi media tanam jamur tiram hanya 31,6\%, sedangkan peserta yang "kurang mengetahui" sebanyak 63,2\% (Gambar 6).

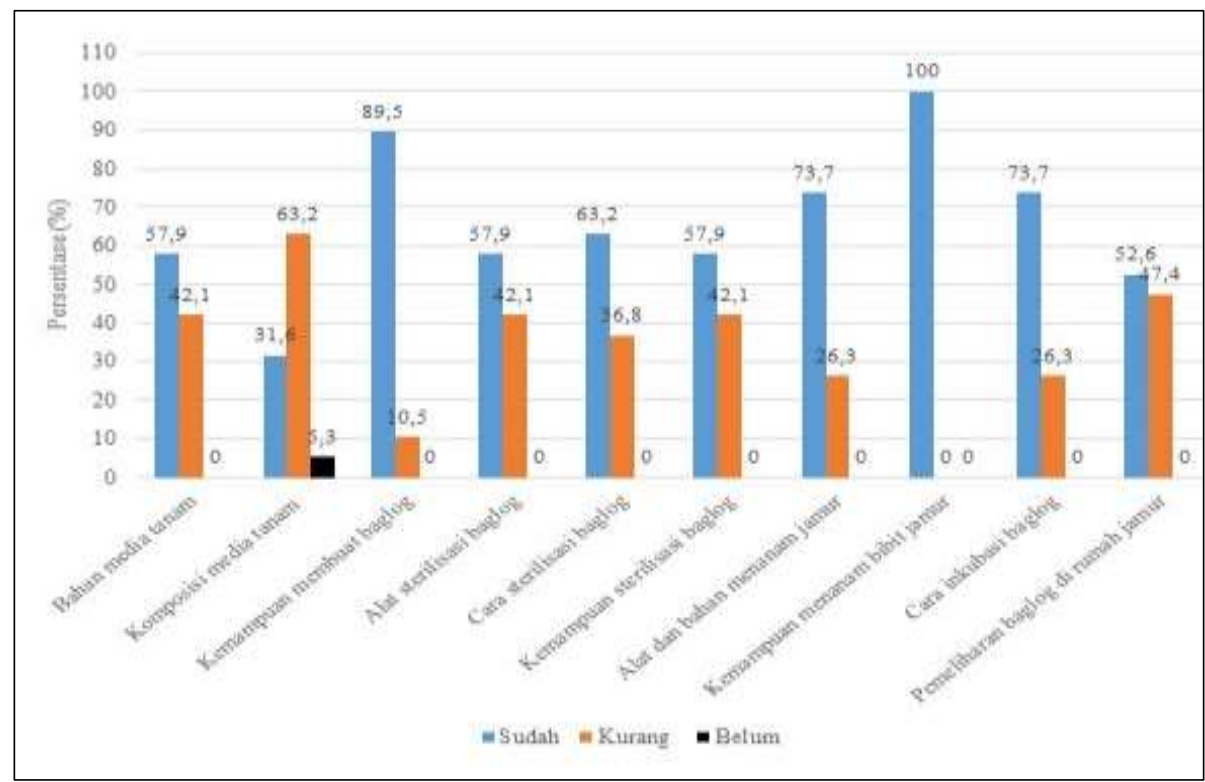

Gambar 6. Penguasaan pengetahuan dan keterampilan siswa SMK-PP Negeri Jambi setelah mengikuti kegiatan pelatihan budidaya jamur tiram

Pada grafik di Gambar 6 menunjukkan bahwa setelah pelatihan, siswa-siswi mampu menguasai beberapa keterampilan dalam budidaya jamur tiram, seperti cara membuat baglog jamur, cara sterilisasi baglog, cara penanaman bibit jamur tiram, cara inkubasi baglog, dan cara pemeliharaan baglog dalam rumah jamur. Persentase siswa yang sudah mampu menguasai 
keterampilan dasar budidaya jamur tiram berkisar 52.6 - 100\%, sedangkan persentase siswa yang kurang mampu menguasai keterampilan budidaya jamur tiram adalah $10.5-47.4 \%$. Hasil analisis ini menunjukkan bahwa beberapa siswa masih memerlukan latihan untuk meningkatkan keterampilannya sehingga dapat melakukan budidaya jamur tiram secara mandiri.

Evaluasi terhadap pelaksanaan kegiatan PKM dalam rangka peningkatan pengetahuan dan minat siswa dalam mengaplikasikan keterampilan yang telah diberikan pada kegiatan pelatihan ini menunjukkan bahwa semua siswa menyatakan bahwa kegiatan pelatihan budidaya jamur tiram bermanfaat untuk menambah keterampilan siswa, $84 \%$ siswa menyatakan mampu untuk membudidayakan jamur tiram setelah mengikuti pelatihan, semua siswa peserta pelatihan mempunyai minat untuk melakukan usaha budidaya jamur tiram. Hal ini menunjukkan bahwa kegiatan pelatihan yang telah dilakukan tidak hanya menambah keterampilan siswa SMK-PP Negeri Jambi, tetapi juga menumbuhkan jiwa kewiraausahaan bagi siswa. Menurut Gayatri dan Rahayu (2015), kegiatan pengabdian dengan metode partisipasif dan praktik langsung serta pemberian motivasi dan pengetahuan kewirausahaan diharapkan dapat menambah wacana dalam mempersiapkan diri berwirausaha. Program kewirausahaan akan membangun pengetahuan dan keterampilan serta menuntut siswa SMK untuk terlibat dalam praktek (Christanti, 2016).

Kegiatan pengabdian kepada masyarakat yang telah dilakukan di SMK-PP Negeri Jambi mendapatkan apresiasi sangat baik dari tim Direktorat Riset dan Pengabdian Masyarakat (DRPM), Kementerian Riset, Teknologi dan Pendidikan Tinggi yang telah melakukan monitoring dan evalusi ke lokasi kegiatan pengabdian kepada masyarakat (Gambar 7). Kegiatan ini diharapkan dapat dikembangkan oleh pihak SMK untuk menjadi salah satu kompetensi yang dimiliki oleh lulusan SMK tersebut.

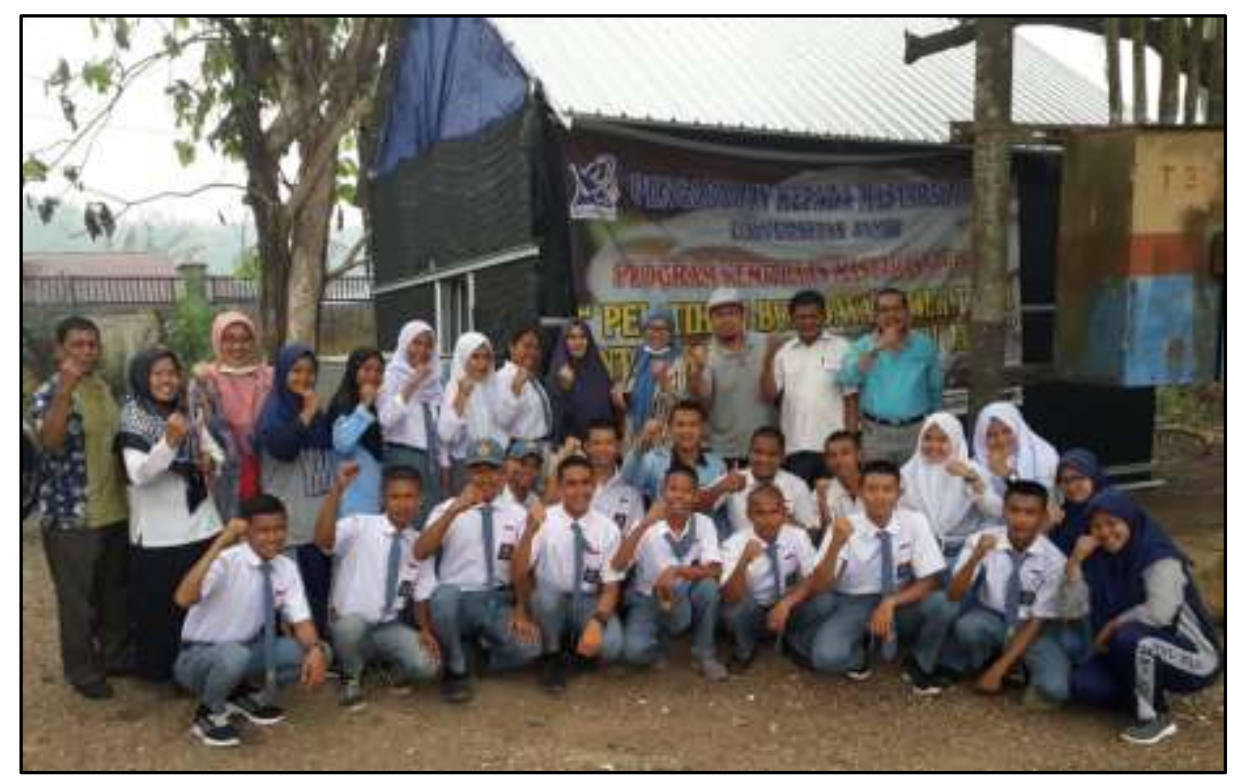

Gambar 7. Siswa-siswi peserta pelatihan bersama Tim Pengabdian Masyarakat dan Tim Monitoring dan Evaluasi dari Direktorat Riset dan Pengabdian Masyarakat (DRPM), Kemenristek Dikti.

\section{KESIMPULAN}

Berdasarkan tahapan kegiatan pengabdian di SMK-PP Negeri Jambi yang telah dilakukan dapat disimpulkan bahwa :

1. Kegiatan penyuluhan yang telah dilakukan mampu meningkatkan pengetahuan siswa SMK-PP Negeri Jambi tentang potensi usaha budidaya jamur tiram.

2. Pelatihan yang telah dilakukan mampu meningkatkan pengetahuan dan keterampilan siswa SMK-PP Negeri Jambi tentang budidaya jamur tiram. 
3. Siswa SMK-PP Negeri Jambi telah menguasai teknik dasar dalam budidaya jamur tiram dan mempunyai minat untuk melakukan usaha budidaya jamur tiram.

\section{UCAPAN TERIMA KASIH}

Penulis mengucapkan terima kasih kepada Direktorat Riset dan Pengabdian Masyarakat Kemenristek Dikti yang telah mendanai kegiatan pengabdian kepada masyarakat ini melalui skim Program Kemitraan Masyarakat Tahun Anggaran 2019.

\section{DAFTAR PUSTAKA}

Achmad, M. , Arlianti, T., \& Azmi, C. (2011). Panduan Lengkap Budidaya Jamur. Jakarta: Penebar Swadaya.

Atmam, A., Situmeang, U., \& Yuvendius, H. (2019). Pelatihan Sablon Manual untuk Kreatifitas Siswa pada SMA Budhi Luhur. Dinamisia : Jurnal Pengabdian Kepada Masyarakat, 3 (1) : 112117.

Christanti, A. (2016). Studi Peranan Pelatihan Kewirausahaan Terhadap Pembentukan Sikap Dan Intensi Kewirausahaan di Sentra Industri Produk Roti Dan Kue Rungkut Lor, Surabaya. Agora, 4 (1) : 242-248.

Gayatri, A. M. \& Rahayu, E. I. (2015). Pemberdayaan Siswa SMK melalui Pelatihan Keterampilan dengan Pemanfaatan Kain Perca sebagai Peluang Usaha. Jurnal Sosio-E-Kons, 7 (3) : 210-215.

Gunawan, A. W. (2000). Usaha Pembibitan Jamur. Jakarta: Penebar Swadaya

Mowsumi, F. R. \& Choudhury, M. B. K. (2010). Oyster Mushroom: Biochemical and Medicinal Prospects Bangladesh. Journal Medical Biochemistry,: 3(1) : 23 - 28.

Susi, N., Rizal, M., \& Mutryarny, E. (2017). Pelatihan Pengolahan Jamur Tiram di Kelurahan Tangkerang Tengah Kecamatan Marpoyan Damai Kota Pekanbaru. Dinamisia : Jurnal Pengabdian Kepada Masyarakat, 1(1), 79-83.

Susilawati \& Raharjo, B . (2010). Budidaya Jamur Tiram (Pleourotus ostreatus) yang ramah lingkungan (Materi Pelatihan Agribisnis bagi KMPH). Balai Pengkajian Teknologi Pertanian. Sumatera Selatan.

Wahzudik, N., Budisantoso, H. T., \& Sulistio, B. (2018). Kendala dan Rekomendasi Perbaikan Pengembangan Kurikulum di Sekolah Menengah Kejuruan. Indonesian Journal of Curriculum and Educational Technology Studies, 6 (2): 87-97.

Wiardani I. 2010. Budidaya Jamur Konsumsi. Lily Publisher. Yogyakarta

Yuliani, Y., Maryanto, M., \& Nurhayati, N. (2018). Karakteristik Fisik dan Kimia Tepung Jamur Merang (Volvariella volvacea) dan Tepung Jamur Tiram (Pleurotus ostreatus) Tervariasi Perlakuan Blansing. Jurnal Agroekoteknologi, 12 (02) : 176-183. 